\title{
ATIVIDADE METABÓLICA DE FIBROBLASTOS HUMANOS DERMAIS CULTIVADOS EM MEMBRANAS DE CELULOSE BACTERIANA COMPÓSITAS COM ALOE VERA
}

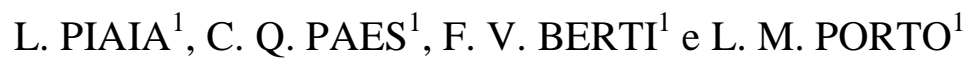 \\ ${ }^{1}$ Universidade Federal de Santa Catarina, \\ Departamento de Engenharia Química e Engenharia de Alimentos \\ E-mail para contato: \{lya, luismar\}@intelab.ufsc.br
}

\begin{abstract}
RESUMO - A incorporação de princípios bioativos extraídos da planta Aloe vera pode ser realizada in situ durante a produção de celulose bacteriana, proporcionando um aumento na funcionalidade dos hidrogéis de celulose bacteriana (CB) quando aplicados como scaffolds na Engenharia de Tecidos. Neste trabalho avaliou-se a atividade metabólica de fibroblastos humanos dermais cultivados in vitro nas membranas de CB-Aloe. Para tanto, MEV foi realizado a fim de avaliar a morfologia celular. A citotoxicidade foi avaliada através da análise de MTS e Live/Dead®. Não foram observados efeitos citotóxicos e houveram mudanças morfológicas significativas devido à adesão das células nas fibras do scaffold. Tais achados demonstram que as alterações morfológicas observadas no citoesqueleto dos fibroblastos são correspondentes à boa adaptação no biomaterial.
\end{abstract}

\section{INTRODUÇÃO}

$\mathrm{Na}$ engenharia de tecidos estão sendo desenvolvidos novos biomateriais, visando melhorar scaffolds que possam ser utilizados como substitutos de órgãos e tecidos, para promover a restauração das funções nativas dos mesmos (Naderi et al., 2011). Estes scaffolds podem ser utilizados como suportes na reconstrução e mimetização de microambientes celulares (Fu et al., 2013). No caso do desenvolvimento de substitutos para a pele os scaffolds servem como 'guias' para as células, favorecendo a adesão, crescimento e diferenciação celular, formando assim uma pele funcional e um tecido estruturado (Zhong et al., 2010).

Os biomateriais que vem sendo desenvolvidos em engenharia de tecidos são quimicamente diversificados como, por exemplo: a poli( $\varepsilon$-caprolactona), a quitosana, o colágeno, a quitina, a elastina, a gelatina, o ácido hialurônico, dentre outros como a celulose bacteriana(Koide et al., 1993;1999; Badylak, 2007). A celulose bacteriana (CB) é um polímero natural, que apresenta fórmula molecular $\left(\mathrm{C}_{6} \mathrm{H}_{10} \mathrm{O}_{5}\right)_{\mathrm{n}}$, com ligações $\beta-(1,4)$, nas quais estão ligadas unidades de D-glicose que possuem interação intramolecular entre o oxigênio e hidrogênio, através de ligações do tipo pontes de hidrogênio (Sjostrom, 1993).

A bactéria que possui capacidade de síntese de CB é conhecida como Gluconacetobacter. Quando for cultivada em meio de cultura contendo diferentes fontes de carbono como, por exemplo: manitol, glicose, sacarose e glicerol excreta nanofibras de celulose pura. Deste modo esta bactéria possibilita a formação de membranas (hidrogéis) com propriedades físicas e químicas 


\section{9 a 22 de outubro de 2014 \\ Florianópolis/SC}

particulares que dependem da composição do meio de cultura. Estas propriedades estão relacionadas à estrutura organizacional das nanofibras de celulose ao longo de sua produção (Haigler et al., 1982; Hutchens et al., 2007) e, consequentemente, das suas propriedades mecânicas.

A celulose produzida extracelularmente apresenta características peculiares, as quais indicam um grande potencial para ser utilizada como biomaterial de engenharia tecidual, medicina regenerativa e outras aplicações biomédicas. A CB é um polímero puro, ultra-fino, que possui uma rede aleatória de fibras, estrutura de rede cristalina única, em nano-escala tridimensional, bem como alta capacidade de absorção de água, resistência mecânica e flexibilidade (Czaja et al., 2006; Fu et al., 2013). Além disso, este material apresenta estrutura variada e com poder de reter 99\% de água em seu peso total (Schrecker and Gostomski, 2005).

Estudos vêm sendo desenvolvidos para aperfeiçoar as propriedades e o uso da CB; portanto, a incorporação de agentes químicos e/ou biológicos nas etapas de produção deste biomaterial pode aumentar o seu espectro de aplicação, melhorando suas propriedades físico-químicas (Chen et al., 2010).

A Aloe vera, também conhecida como babosa, possui inúmeras moléculas bioativas em sua composição, com potencial para ser utilizada na cicatrização de feridas. A penetração do gel de Aloe vera no tecido lesionado pode impedir o crescimento de bactérias, fungos e vírus, pois este gel tem poder antiinflamatório e imunoregulador (Hutter et al., 1996; Das et al., 2011).

Em função das inúmeras propriedades promissoras da celulose bacteriana e da Aloe vera, novos biomateriais foram produzidos em nosso laboratório com base na combinação CB-Aloe. O objetivo deste trabalho foi avaliar a atividade metabólica dos fibroblastos humanos da derme cultivadas in vitro nas membranas de CB-Aloe.

\section{MATERIAIS E MÉTODOS}

\subsection{Produção de membranas de celulose bacteriana}

As membranas de CB foram produzidas utilizando inóculo da bactéria $G$. hansenii ATCC 23769, obtida da "Coleção da Cultura Tropical (CCT)", da Fundação André Tosello, Campinas SP. O inóculo foi produzido três dias antes do início dos experimentos; assim, obteve-se uma solução de inóculo estoque, cuja adição, à base de $10 \%$ (v/v), ao meio de cultura, permitiu a produção de diversas membranas. O meio Manitol foi utilizado para cultivo das membranas (CB) sendo que o mesmo contém: $25 \mathrm{~g}$ de manitol, $5 \mathrm{~g}$ de extrato de levedura e $3 \mathrm{~g}$ de peptona diluídos em $1 \ell$ de água destilada. $\mathrm{O} \mathrm{pH}$ do meio foi ajustado em 6,6 e esterilizado por autoclavagem no período de 20 minutos a $121^{\circ} \mathrm{C}$. As membranas de $\mathrm{CB}$ foram produzidas em placas de cultura de 24 poços (TPP, Switzerland) sendo que em cada poço foram adicionados $1000 \mu \ell$ da solução de inóculo e meio de cultura manitol. As placas de cultura de 24 poços foram mantidas em cultura estática à temperatura de $25^{\circ} \mathrm{C}$, por um período de dez dias. Após o décimo dia, as membranas de $\mathrm{CB}$ que cresceram na interface líquido/ar de cada poço de cultura foram então removidas para início do processo de purificação. 


\section{9 a 22 de outubro de 2014 \\ Florianópolis/SC}

\subsection{Produção, purificação e esterilização das membranas de celulose bacteriana com frações de Aloe vera (CB-Aloe)}

A produção da CB-Aloe foi realizada conforme descrito na Seção 2.1. Contudo, modificações nas proporções de volume de meio com diferentes soluções do extrato de Aloe vera na proporção foram também consideradas. Formando desta forma três membranas distintas, definidas como: CB-Gel, CB-Gel Total, CB-FP1. A membrana CB-Gel é formada por uma solução de gel do extrato de Aloe vera sem as fibras. Já A membrana CB-GelTotal é formada por uma solução do extrato de Aloe vera com as fibras. Por fim a membrana CB-FP1 é formada por uma solução 1 g.L. L $^{-1}$ de FP1 ( solução de gel do extrato de Aloe vera deixado em solução com álcool etílico por 24 horas. $\mathrm{O}$ floculado então autoclado e liofilizado).

Solução de $60 \%$ de cada destas soluções, com $10 \%$ de meio e meio manitol foram então homogeneizadas e adicionadas nas placas de cultura de 24 poços; em cada poço, o volume final foi de $1000 \mu \ell$. Finalizados dez dias de cultura bacteriana houve a formação de membranas de CB e CB-Aloe na interface líquido/ar de cada poço de cultura; as mesmas foram transferidas para um frasco que continha uma solução de $\mathrm{NaOH} 0,1 \mathrm{M}$, e mantidas em $\mathrm{NaOH}$ por $24 \mathrm{~h}$ a $50^{\circ} \mathrm{C}$ para remoção de bactérias e/ou resíduos, que poderiam estar retidos nas redes de nanofibras da celulose bacteriana. Em seguida as membranas foram lavadas três vezes com água destilada; na última lavagem o $\mathrm{pH}$ foi ajustado para 7 e as membranas de CB e CB-Aloe foram então esterilizadas por autoclavagem por um período de $20 \mathrm{~min}$ a $121^{\circ} \mathrm{C}$, e mantidas em local protegido até utilização nos experimentos de cultura de células.

\subsection{Culturas de células de fibroblastos dermais humanos adultos (HDFa)}

A dispersão da cultura de células de fibroblastos dermais humano adultos (HDFa) (Invitrogen) foi mantida em meio de cultura celular Dulbecco's modified Eagle's medium (DMEM) (suplementado com $10 \%$ de soro fetal bovino e $1 \%$ de penicilina/estreptomicina em atmosfera úmida, a $37{ }^{\circ} \mathrm{C}$ com $5 \%$ de $\mathrm{CO}_{2}$ ), utilizando uma densidade celular de $2,5 \times 10^{4}$ cells $\cdot \mathrm{cm}^{-2}$ em cada placa de petri (TPP, Switzerland) para propagação celular. As células HDFa foram utilizadas nas passagens de 5 a 9 .

\subsection{Atividade metabólica e proliferação celular}

A atividade metabólica e a proliferação foram determinadas pela atividade mitocondrial das células através do ensaio colorimétrico do MTS (Promega). O ensaio de MTS [3-(4,5dimetiltiazol-2-il)-5-(3-carboximetoxifenil)-2-(4-sulfofenil)-2H-tetrazólio] é um método utilizado para determinar a atividade metabólica. As células de HDFa foram semeadas na superfície mais porosa das membranas em estudo (CB, CB-Gel, CB-Gel Total, CB-FP1), cultivadas na densidade de $10^{5}$ células/membrana. A atividade metabólica e proliferação celular foram avaliadas em função do tempo, para 1, 2, 3, 7 e 20 dias de cultura. Para cada tempo avaliado no ensaio do MTS, o meio de cultura era removido, as amostras lavadas três vezes com PBS e transferidas para uma nova placa de cultura. Então, $300 \mu \ell$ de meio de cultura e $60 \mu \ell$ do reagente MTS foram adicionados em cada poço da placa de cultura com as amostras. As placas de cultura eram incubadas por $1 \mathrm{~h}$ a $37^{\circ} \mathrm{C}$ em atmosfera de $5 \%$ de $\mathrm{CO}_{2}$ e, logo após, a solução era homogeneizada e $100 \mu \ell$ da solução de cada amostra eram transferidos para uma nova placa de cultura de 96 poços. A leitura da absorbância da solução a $490 \mathrm{~nm}$ foi analisada em leitor de microplacas 
(Thermo Plate - TP Reader). Paralelamente ao ensaio de MTS foi realizada a análise qualitativa do ensaio Live/Dead® ${ }^{\circledR}$ O kit Live/Dead® Viability/Cytotoxicity (Invitrogen) é utilizado somente com células de mamíferos, e mede a atividade intracelular das esterases (calceína) e a integridade da membrana plasmática (homodímero de etídio). Uma solução A constituída por calceína: homodímero de etídio (4:1) em PBS foi preparada e $100 \mu \ell$ desta solução foram adicionados sobre cada amostra. Logo após, a placa de cultura foi incubada por 30 minutos a $37{ }^{\circ} \mathrm{C} \mathrm{em}$ atmosfera de $5 \%$ de $\mathrm{CO}_{2}$ e, após incubação, as amostras foram montadas em lâminas e visualizadas no microscópio de fluorescência (Eclipse Ci-L, Nikon, Japão).

\subsection{Morfologia e adesão celular}

A morfologia das membranas CB-Aloe e a capacidade de adesão das células de fibroblastos humanos da derme cultivadas nas membranas CB-Aloe foram avaliadas utilizando a técnica de Microscopia Eletrônica de Varredura. As membranas foram secas por ponto crítico, foram distribuídas sobre fitas de carbono que estavam aderidas sobre os stubs e então recobertas com uma camada dupla de ouro. Após recobrimento, as amostras foram analisadas por MEV no Laboratório Central de Microscopia Eletrônica (LCME/UFSC), utilizando o equipamento JEOL JSM - 6390LV.

\subsection{Análise estatística}

As comparações entre os grupos foram analisadas pela variância one-way, ANOVA, seguido do teste de Tukey. As diferenças foram consideradas significativas quando $\mathrm{p}<0,05$.

\section{RESULTADOS E DISCUSSÃO}

\subsection{Microestrutura das membranas CB-Aloe sem adesão celular}

A Figura 1 mostra micrografias das membranas CB-Aloe produzidas de modo estático. Pode-se observar que a estrutura da CB (a) e CB-Aloe (b, c, d) possui em sua extensão uma rede de fibras entrelaçadas com diferentes porosidades, organizadas de forma randômica.

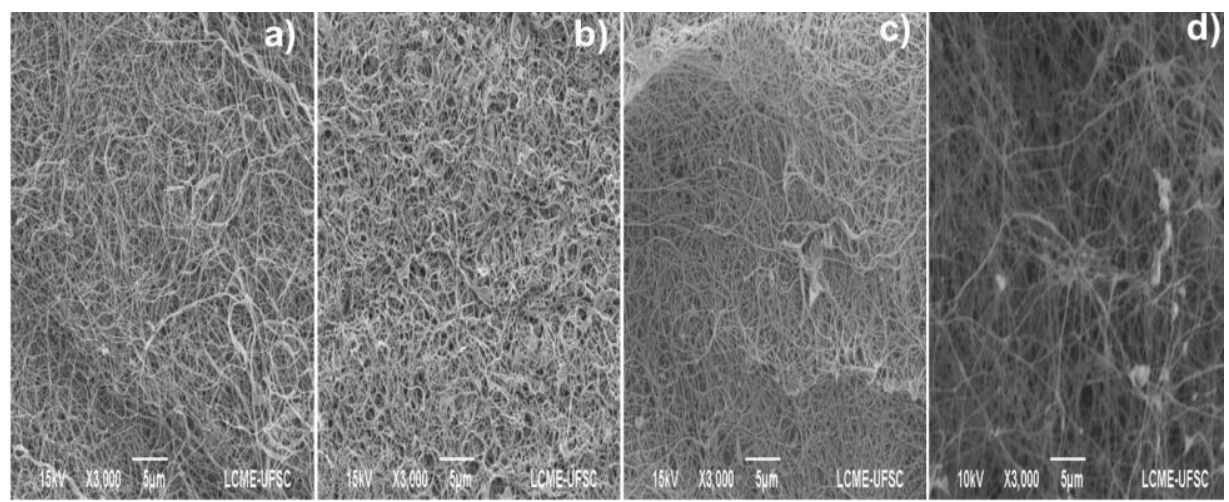

Figura 1 - Micrografias das membranas CB-Aloe. a) CB, b) CB-Gel, c) CB-Gel Total e d) CB-FP1. Membranas com fração de $60 \%$ de Aloe vera. Imagens amplificadas $3000 \times$. 


\subsection{Atividade metabólica e proliferação celular}

Os ensaios de atividade metabólica e proliferação celular foram realizados com células da derme humana in vitro avaliando-se o comportamento celular em até 20 dias de cultura. Os resultados obtidos nestes ensaios são mostrados na Figura 2.

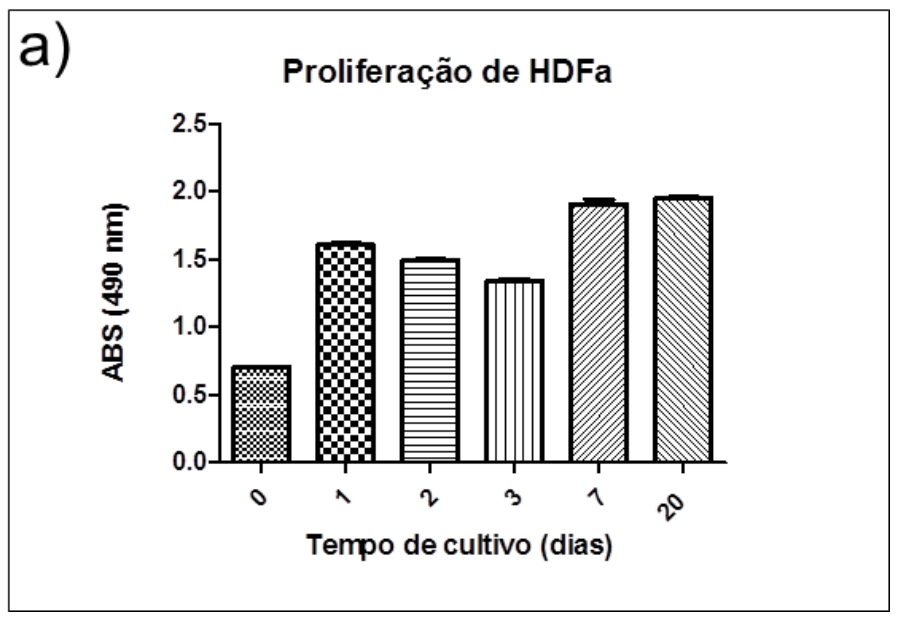

b)
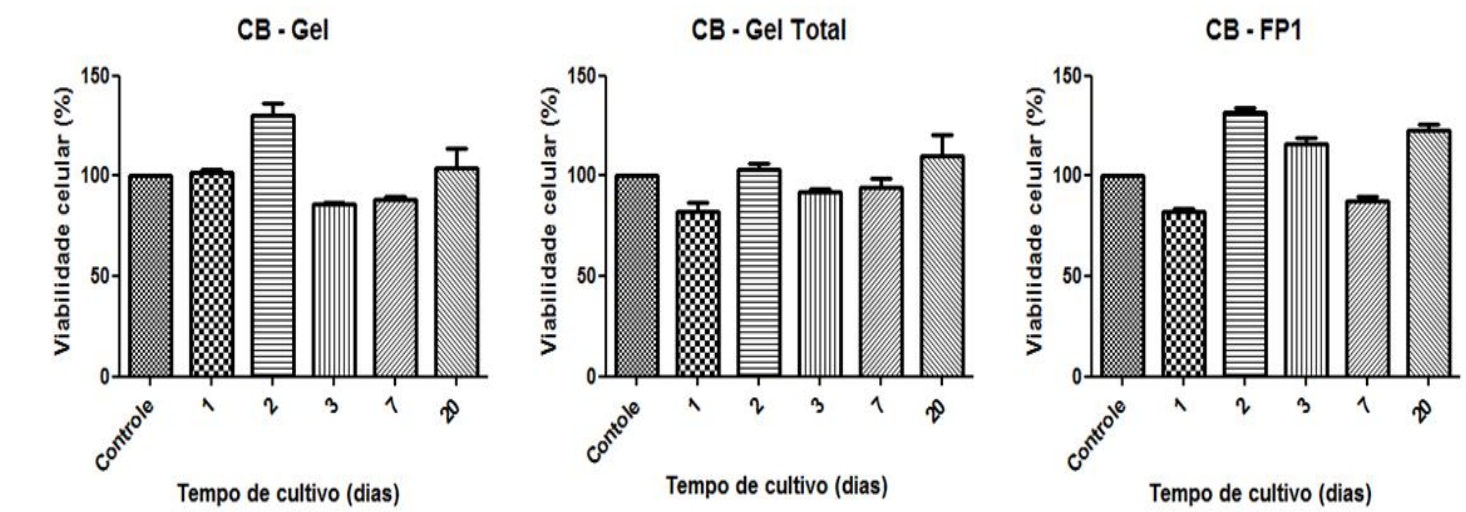

Figura 2 - (a) Proliferação celular de células epiteliais, fibroblastos (HDFa), na placa de cultura, no período total de 20 dias. (b) Viabilidade de HDFa em membranas de CB, CB-Gel, CB-

Gel Total, CB-FP1, avaliadas por MTS para 1, 2, 3, 7 e 20 dias.

A atividade metabólica e proliferação das células HDFa cultivadas na placa estão mostradas na Figura 2 (a). Pode-se observar que a atividade metabólica e proliferação das HDFa se mantêm por 20 dias quando cultivadas em placas de cultura. Observa-se que a atividade metabólica diminui a partir do primeiro dia até o terceiro dia de cultura. Após 7 dias de cultura as células atingem uma taxa de atividade metabólica que permanece constante até o vigésimo dia de cultura. Após analisar o comportamento destas células em placas de cultura cultivou-se as HDFa na superfície porosa das membranas de CB-Aloe. 
A Figura 2 (b) mostra os resultados da atividade metabólica e proliferação das HDFa cultivadas na superfície porosa das membranas de CB-Aloe com distintas composições, obtidos em 20 dias de cultura, com barras de erro $(\mathrm{n}=4)$. Identifica-se que a atividade metabólica da HDFa na CB-Aloe estão acima de $80 \%$ ao longo do tempo de cultivo. Analisando a CB-Gel podemos identificar que após o segundo dia de cultura a atividade metabólica diminuiu. Posteriormente esta atividade metabólica aumenta até o último dia de cultura. Este comportamento foi observado também na CB-Gel Total. Contudo, com a CB-FP1 a atividade metabólica após o segundo dia de cultura foi diminuída, mantendo-se até constante até o sétimo dia; posteriormente, ocorreu um aumento desta atividade. Diferenças significativas $(\mathrm{p}<0,05)$ foram observadas no segundo e terceiro dias de cultivo para as membranas CB-Gel e CB-FP1.

A viabilidade das $\mathrm{HDFa}$ cultivadas nas membranas CB-Aloe foi comprovada qualitativamente através do ensaio Live/Dead®, mostrado na Figura 3.

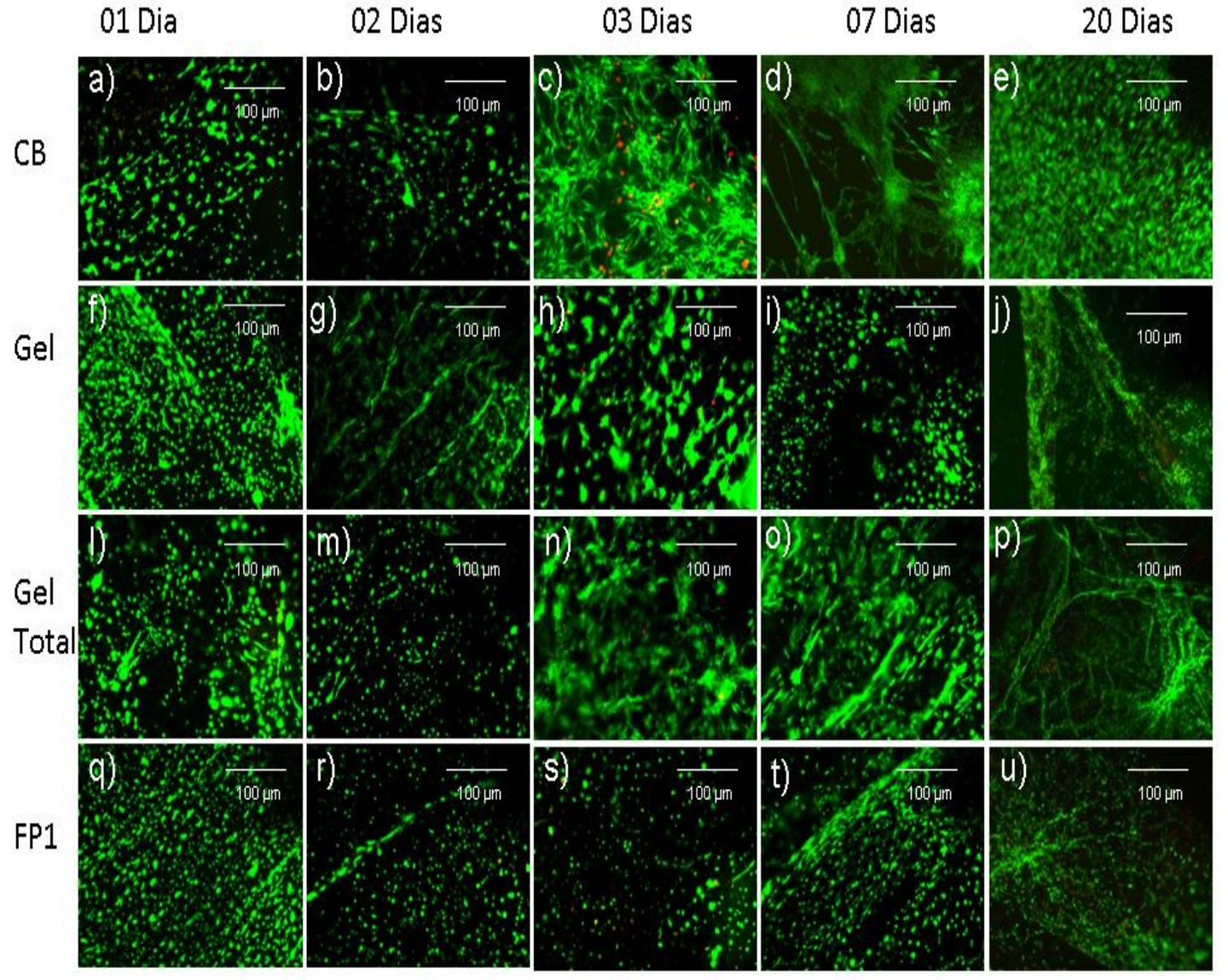

Figura 3 - Viabilidade das células de HDFa, utilizando o kit Live/Dead®. Em verde (calceína) podem ser visualizadas as células viáveis e em vermelho (homodímero de etídio) as células mortas.

Na Figura 3 podemos identificar qualitativamente, pelas imagens obtidas do ensaio com o kit Live/Dead®, a viabilidade referente à CB-Aloe ao longo do tempo de experimento. Estes resultados comprovam os resultados de MTS e demonstra a boa à viabilidade celular nestas membranas. 


\subsection{Adesão e morfologia celular}

A adesão e a morfologia das células HDFa foram avaliadas utilizando microscopia eletrônica de varredura (MEV). O resultado pode ser observado na Figura 4.

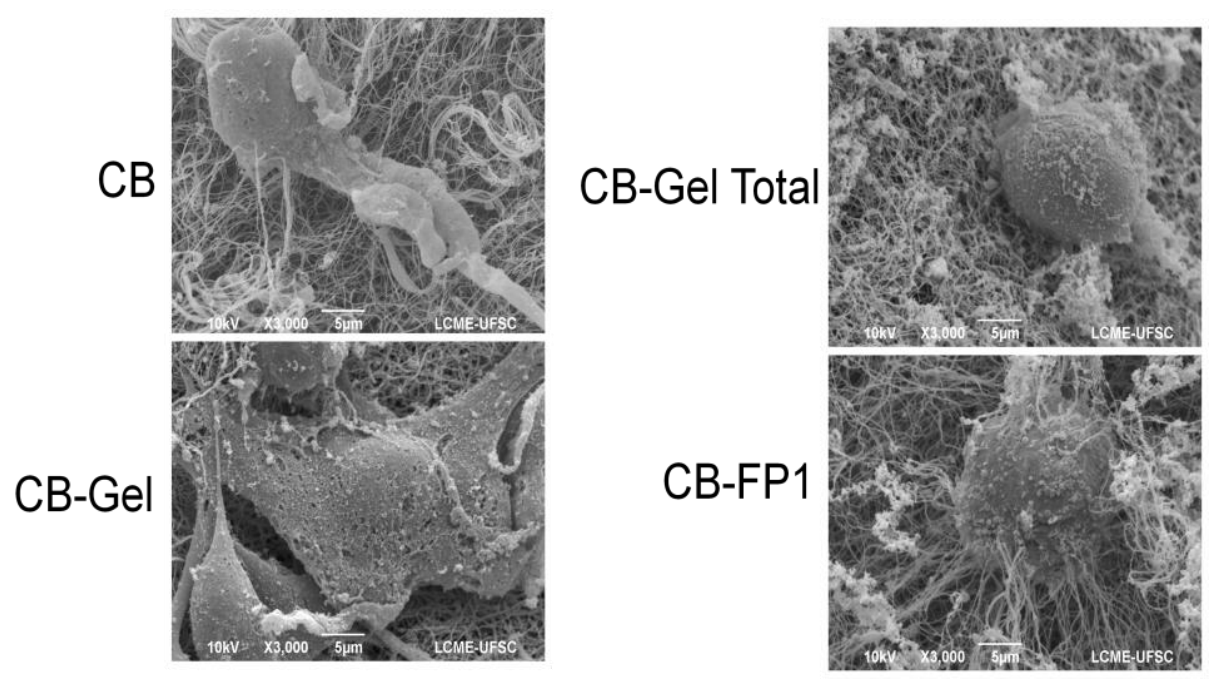

Figura 4 - Morfologia e adesão de células HDFa cultivadas nas membranas CB-Aloe. Como ilustrado na figura, temos: (a) CB; (b) CB-Gel; (c) CB-Gel Total e (d) CB-FP1.

A Figura 4 mostra a morfologia das células HDFa no terceiro dia de cultivo. Nas imagens observamos em (a) e (b) o estado morfológico das células com comportamento natural, em forma alongada. Entretanto, nas demais membranas são mostradas imagens em que as nanofibras de celulose no compósito CB-Aloe estão entrelaçadas, fixando ainda mais a célula no biomaterial. Observa-se também que a morfologia é mais arredondada, não aderida.

\section{CONCLUSÕES}

Os resultados obtidos quanto à atividade metabólica das células de fibroblastos humanos cultivados nas membranas de CB-Aloe comprovam que os materiais desenvolvidos não afetam a viabilidade celular. Através da análise qualitativa (Live/Dead®) foi possível observar que as células permanecem viáveis durante 20 dias de cultura nas membranas de CB-Aloe. As células aderidas nas membranas de CB-Aloe, e após três dias de cultura, encontram-se morfologicamente espraiadas na membrana CB-Aloe. Podemos identificar que a membrana CB-Gel demonstrou maior manutenção da viabilidade celular no período estudado.

\section{REFERENCIAS}

BADYLAK, S. F. The extracellular matrix as a biologic scaffold material. Biomaterials, v.28, n.25, p. 3587-93, 2007.

CHEN, P.; CHO S.; JIN, H.-J. Modification and applications of bacterial celluloses in polymer science. Macromol. Res., v.18, n. 4, p. 309-320, 2010.

CZAJA, W. K.; YOUNG, D. J.; KAWECKI, M.; BROWN, R. M. The Future Prospects of Microbial Cellulose in Biomedical Applications. Biomacromolecules, v.8, n.1, p.1-12, 2006. 
DAS, S.; MISHRA, B.; GILL, K.; ASHRAF, M. S.; SINGH, A. K.; SINHA, M.; SHARMA, S.; XESS, I.; DALAL, K.; SINGH, T. P.; DEY, S. Isolation and characterization of novel protein with anti-fungal and anti-inflammatory properties from Aloe vera leaf gel. Int. J. Biol. Macromol., v. 48, n.1, p. 38-43, 2011.

FU, L.; ZHANG, J.; YANG, G. Present status and applications of bacterial cellulose-based materials for skin tissue repair. Carbohyd. Polym., v. 92, n. 2, p. 1432-1442, 2013.

HAIGLER, C. H.; WHITE, A. R.; BROWN, R. M.; COOPER, K. M. Alteration of in vivo cellulose ribbon assembly by carboxymethylcellulose and other cellulose derivatives. J. Cell Biol., v. 94 , n. 1, p. 64-69, 1982.

HUTCHENS, S. A.; LEÓN; R. V.; O'NEILL, H. M.; EVANS, B. R. Statistical analysis of optimal culture conditions for Gluconacetobacter hansenii cellulose production. Lett. Appl. Microbiol., v. 44, n. 2, p. 175-180, 2007.

HUTTER, J. A.; SALMAN, M.; STAVINOHA, W. B.; SATSANGI, N.; WILLIAMS, R. F.; STREEPER, R. T.; WEINTRAUB, S. T. Antiinflammatory C-Glucosyl Chromone from Aloe barbadensis. J. Nat. Prod., v. 59, n. 5, p. 541-543, 1996.

IGUCHI, M.; YAMANAKA, S.; BUDHIONO, A. Bacterial cellulose-a masterpiece of nature's arts. J. Mater. Sci., v. 35, n. 2, p. 261-270, 2000.

KOIDE, M.; OSAKI, K.; KONISHI, J.; OYAMADA, K.; KATAKURA, T.; TAKAHASHI, A.; YOSHIZATO, K. A new type of biomaterial for artificial skin: dehydrothermally cross-linked composites of fibrillar and denatured collagens. J. Biomed. Mater. Res., v. 27, n. 1, p. 79-87, 1993.

MEVES, A.; STOCK, S. N.; BEYERLE, A.; PITTELKOW, M. R.; PEUS, H. H( $\left.{ }_{2}\right) \mathrm{O}\left({ }_{2}\right)$ mediates oxidative stress-induced epidermal growth factor receptor phosphorylation. Toxicol. Lett., v. 122, n. 3, p. 205-14, 2001.

MICHAELIS, S.; ROBELEK , R.; WEGENER, J. Studying cell-surface interactions in vitro: a survey of experimental approaches and techniques. Adv. Biochem. Eng. Biotechnol., v. 126, p. 3366, 2012.

NADERI, H.; MATIN, M. M.; BAHRAMI, A. R. Review paper: critical issues in tissue engineering: biomaterials, cell sources, angiogenesis, and drug delivery systems. J. Biomater. Appl., v. 26, n. 4, p. 383-417, 2011.

PÉREZ, R. A.; WON; J.-E.; KNOWLES, J. C.; KIM, H.-W. Naturally and synthetic smart composite biomaterials for tissue regeneration. Adv. Drug. Deliver. Rev., n. 0, 2013.

SCHRECKER, S. T.; GOSTOMSKI, P. A. Determining the Water Holding Capacity of Microbial Cellulose. Biotechnol. Lett., v. 27, n. 19, p. 1435-1438, 2005.

SJOSTROM, E. Wood chemistry: fundamentals and applications, 1993.

ZHONG, S. P.; ZHANG Y. Z.; LIM, C. T. Tissue scaffolds for skin wound healing and dermal reconstruction. Wil. Interdiscip. Rev. Nanomed. Nanobiotechnol., v. 2, n. 5, p. 510-25, 2010. 